\title{
Synergistically Degradation of Cellulose by Anlpmo14g, A Fungal Lytic Polysaccharide Monooxygenase from Aspergillus Niger
}

\section{Lijuan Ma ( $\square$ malj@tust.edu.cn )}

Tianjin University of Science and Technology https://orcid.org/0000-0003-2043-9961

\section{Yaqi Wang}

Tianjin University of Science and Technology

\section{Yining Liu}

Tianjin University of Science and Technology

\section{Linlin Fan}

Tianjin University of Science and Technology

\section{Yuying Cao}

Tianjin University of Science and Technology

\section{Shuang Wang}

Tianjin University of Science and Technology

\section{Hongxuan Li}

Tianjin University of Science and Technology

\section{Liping Du}

Tianjin University of Science and Technology

Jihong Huang

Henan University of Technology

\section{Hong Wang}

Wuliangye Group

\section{Research Article}

Keywords: Aspergillus niger, Lytic polysaccharide monooxygenases, AnLPM014g, cellulose hydrolysis, synergism activity, homology modeling

Posted Date: January 19th, 2022

DOI: https://doi.org/10.21203/rs.3.rs-1226943/v1

License: (c) (1) This work is licensed under a Creative Commons Attribution 4.0 International License. Read Full License 


\section{Abstract}

The auxiliary active family 9 (AA9) of fungal lytic polysaccharide monooxygenases (LPMOs) can improve the lignocellulosic hydrolysis through an oxidative mechanism. Aspergillus niger is an important industrial producer of glycoside hydrolases, but little research on LPMOs in A. niger have been reported. This study aimed to research the biochemical characteristics of LPMOs from A. niger and the synergy with cellulase on cellulose hydrolysis. Reducing sugar produced when An LPM014g acted on Carboxyl Methyl Cellulose (CMC), Avicel ${ }^{\circledR}$, xylan, filter paper, straw and corn cobs, and MALDI-TOF/TOF mass spectrometry analysis indicated that it oxidatively cleaved the glycosidic bonds of Avicel $\AA$ at $\mathrm{C} 1$ position. The addition of An LPMO14g into the hydrolysis systems of Avicel ${ }^{\circledR}$ and straw catalyzed by cellulase could increase the yields of reducing sugar by $92.66 \%$ and $141.42 \%$, respectively. Homology modeling displayed that the residues $\mathrm{H} 1, \mathrm{H} 86, \mathrm{Y} 175, \mathrm{Y} 24, \mathrm{P} 83$ and $\mathrm{Y} 212$ of An LPM014g played an important role in the catalytic process of cellulose. This study enriches the AA9 LPMO family and provides a promising candidate for the high-efficient enzyme cocktails for lignocellulose degradation.

\section{Introduction}

Lignocellulose is the most abundant renewable biomass resource in nature which can be converted into a variety of energy sources, materials and chemicals through biochemical technology (Jonsson et al. 2013). Enzymatic hydrolysis of lignocellulose is a very important step in its degradation and utilization process (Lynd et al. 2005). However, the complex network structure of lignocellulose will hinder the binding of cellulase, resulting in the limitation the enzymatic efficiency and high cost of biomass energy (Cheng et al. 2011). It is a gigantic technical challenge that the inherent stubborn network structure of plant cell walls is broken down in a cost-effective manner at scales sufficient (Payne et al. 2011).

For a long time, it has been thought that the degradation of cellulose is completed by glycoside hydrolase. However, complex hydrogen bond network formed inside and between the cellulose molecular chains seriously affects the hydrolysis rate of glycoside hydrolase such as exocellulase (Reese et al. 2011). In 2010, Harris et al. found that cellulase enzymes originally belonging to the GH61 family efficiently cleave the glycosidic bonds of crystalline cellulose by redox reaction (Harris et al., 2010). This report has aroused great interest among scholars in related fields (Kim et al. 2009). These enzymes are collectively referred to as lytic polysaccharide monooxygenases (LPMOs). In 2013, the carbohydrate active enzyme database (CAZy) classified LPMOs and Lignin degrading enzymes into a large group, collectively referred to as "auxiliary activities" (AA) (Levasseur et al. 2013).

LPMOs are mainly distributed in AA9 (formerly GH61 family) acting on cellulose, AA10 (formerly CBM33 family), AA11 acting on chitin, and AA13 family acting on starch (Forsberg et al. 2011; Beeson et al. 2012). In recent years, reports on AA9 LPMOs are increasing, mainly focusing on the clonal expression of proteins, structural properties and hydrolysis applications. In terms of structural properties, all LPMOs have in common a slightly distorted fibronectin-like/immunoglobulin-like $\beta$-sandwich core structure 
consisting of two $\beta$-sheets containing a total of seven or eight $\beta$-strands (Vaaje-Kolstad et al. 2017). TrCel61B was reported as the first crystalline structure of GH61 family (Karkehabadi et al. 2008); Borisova et al. studied the crystal structure of the catalytic domain of NcLPMO9C from Neurospora crassa and found an extended, highly polar substrate-binding surface well suited to interact with a variety of sugar substrates (Borisova et al. 2015). Besides, AA9 with activities toward various substrates have been reported, including corn stover, poplar, lodgepole pine, oak, kenaf, hemicellulose and cellooligosaccharides, etc (Agger et al. 2014; Hu et al. 2014; Jung et al. 2015). In addition, Pichia pastoris was reported as a suitable expression host for the LPMO Cel61A from Trichoderma reesei, with a protein yield of more than $400 \mathrm{mg} / \mathrm{L}$ during fermentation (Tanghe et al. 2015). Kim et al. reported that a recombinant AA9 from Chaetomium globosum (CgAA9, $0.9 \mathrm{mg} / \mathrm{g}$ cellulose) exhibited 1.7-fold synergism in the hydrolysis of Avicel when incubated with 0.9 filter paper units of Celluclast $1.5 \mathrm{~L} / \mathrm{g}$ cellulose (Kim et al. 2015). In summary, AA9 becomes a research hotspot with great potential and industrial value.

AA9 is mainly derived from filamentous fungi such as $T$. reesei, $N$. crassa and Aspergillus nidulans (Borisova et al. 2015; Li et al. 2012; Kjaergaard et al. 2012; Tan et al. 2015). AA9 plays an important role in promoting the degradation of lignocellulose, but research on its source and species is still limited. Studying the characteristics of different types and sources of AA9 LPMOs is of great significance for improving cellulose degradation efficiency and reducing degradation costs. Aspergillus niger is an important filamentous fungus that can efficiently synthesize and secrete glycoside hydrolase. According to CAZy Database, $A$. niger CBS 513.88 contains seven genes encoding polysaccharide monooxygenase from AA9, which has important research value. In our previous research, the gene encoding $A n L P M 015 \mathrm{~g}$ derived from A. niger was successfully cloned and expressed and it was also found that $A n \mathrm{LPMO} 15 \mathrm{~g}$ significantly improved the catalytic efficiency of cellulase for Avicel® and lignocellulose (Du et al. 2018), but no other researchers have reported on it yet.

In this study, the gene An14g02670 from A. niger CBS 513.88, which encodes the polysaccharide monooxygenase from AA9, was heterologously expressed in P. pastoris GS115. The substrate specificity of $A n L P M 014 \mathrm{~g}$ and its cleavage mode on cellulose were investigated as well as the synergistic activity of AnLPM014g with cellulase. Factors affecting synergy including $\mathrm{pH}$, metal ions, enzyme dosage, and types of reducing electron donors were studied. Finally, key residues of $A n L P M 014 \mathrm{~g}$ were investigated by homology modeling.

\section{Materials And Methods}

\subsection{Strains, enzymes and chemicals}

A. niger CBS 513.88 (CBS, Institute of the Royal Netherlands Academy of Arts and Sciences, Utrecht, Netherlands) was used as the source for AnLPM014g. P. pastoris GS115, expression vector pPIC9K and Escherichia coli DH5a were purchased from Invitrogen Corporation (Invitrogen, Carlsbad, CA). Cellulase (CellicCtec2, 180 FPU/mL) was kindly presented by Novozymes (China) Biotechnology Co., Ltd., Tianjin, 
China. All the chemicals used in this research were of analytical grade and purchased from Sigma-Aldrich China Inc.

\subsection{Cloning, expression and purification of $A n L P M 014 \mathrm{~g}$}

Methods referred to our previous study (Du et al. 2018). Briefly, total RNA was extracted from A. niger and then reverse transcribed into cDNA using the TMRT kit (TaKara, China). The sequences of primers were $5^{\prime}$ GCGCGAATTCCACGGTCACGTCACTAACCTCGTCGT-3' and 5'-

TATATGCGGCCGCTTAGTGATGGTGATGGTGATGAGCACTAGCAATGCACTGGTAGTAGTA-3', in which the underlined sequence was that of His tag. The purified gene was ligated to PPIC9K and transformed $E$. coli. DH5a. PCR validation was performed using the universal primer AOX1, and the correctly ligated plasmid was electrotransformed into P. pastoris GS115. Positive recombinants after colony-PCR verification were inoculated into BMGY plates (1\% yeast extract, $2 \%$ peptone, $1.34 \%$ YNB, $4 \times 10-5 \%$ biotin, $1 \%$ glycerol, $100 \mathrm{mM}$ potassium phosphate buffer $\mathrm{pH} 6.0$, dissolved in deionized water, $121^{\circ} \mathrm{C}$, autoclaved for $20 \mathrm{~min}$ ) for expression and verified by Sodium dodecyl sulfate-polyacrylamide gel electrophoresis (SDS-PAGE). The culture supernatant loaded onto the Ni-Agarose Resin for $6 \times$ His-Tagged Proteins (CWBIO, Beijing, China) and the protein purity was analyzed by SDS-PAGE.

\subsection{Substrate specificity analysis}

Five substrates including Avicel ${ }^{\circledR}$ (Solarbio, China), CMC (Sigma, China), straw (the suburb of Tianjin, China with the composition of $33.5 \%$ hemicellulose, $36.4 \%$ cellulose, and $11.2 \%$ lignin), corn cob (the suburb of Tianjin, China with the composition of $34.32 \%$ hemicellulose, $35.34 \%$ cellulose, and $15.81 \%$ lignin), filter paper (Solarbio, China) and xylan (Sigma, China) were used in the experiment of substrate specificity analysis. The reaction system contained $0.01 \mathrm{~g}$ of substrate and purified protein with a concentration of $0.9 \mathrm{mg} / \mathrm{g}$ substrate, and ascorbic acid was added to a final concentration of $1 \mathrm{mM}$. The volume was supplemented to $1 \mathrm{~mL}$ with a $50 \mathrm{mM}$ sodium acetate buffer solution of pH 5.0. After reacting at $50^{\circ} \mathrm{C}, 200 \mathrm{rpm}$ for $48 \mathrm{~h}$, the reaction was terminated by heating in a boiling water bath for $5 \mathrm{~min}$, and the supernatant was collected by centrifugation at $12000 \mathrm{rpm}$ for $1 \mathrm{~min}$. The yield of reducing sugar was measured by DNS method (Miller. 1959). The reaction system without AnLPMO14g was used as a control.

\subsection{Product analysis of AnLPMO14g on cellulose by MALDI-TOF/TOF}

The supernatant of the lytic reaction of cellulose catalyzed by $A n L P M 014 \mathrm{~g}$ was purified and desalted using AMBERLITE IR-120 resin (Bellancom Chemistry Co., Ltd.) and then analyzed on an ultraflextreme MALDI-TOF/TOF mass spectrometry (MS) (Matrix-Assisted Laser Desorption/lonization Time of Flight) spectrometer (Bruker Daltonics, Bremen, Germany) which was controlled using Flex Control 3.0 software 
package. The sample processing and analysis method was referred to the previous report (Du et al. 2018).

\subsection{Synergistic hydrolysis activity of $A n L P M 014 \mathrm{~g}$ with Cellulase}

Three systems were used including systems containing only $A n L P M 014 \mathrm{~g}$, systems containing only a commercial cellulase, and systems containing both $A n L P M 014 \mathrm{~g}$ and cellulase. Reaction systems were prepared according to Section 2.3, and the dosage of $A n \mathrm{LPMO} 14 \mathrm{~g}$ and cellulase were $0.9 \mathrm{mg} / \mathrm{g}$ and 0.9 $\mathrm{FPU} / \mathrm{g}$ substrate, respectively. Reactions were carried out at $50{ }^{\circ} \mathrm{C}, 200 \mathrm{rpm}$ for $48 \mathrm{~h}$ and DNS method was used to determine the reducing sugar production. Degree of synergism (DS) was calculated to evaluate the synergistic ability of the two enzymes:

$$
\mathrm{DS}=C_{A+C} /\left(C_{C}+C_{A}\right) \quad \nabla 1 \rrbracket
$$

In equation $1, C_{A+C}$ indicates the reducing sugar yield of $A n L P M 014 \mathrm{~g}$ and cellulase, $C_{C}$ indicates the reducing sugar yield of cellulase alone, and $C_{A}$ indicates the reducing sugar yield of $A n L P M 014 \mathrm{~g}$ alone. If DS is greater than 1, it means that there is a promotion between the two enzymes; if it is around 1, it means that the two may be a simple superposition; if it is significantly less than 1 , it means that the two may be mutually inhibited by the competition substrate.

\subsection{Effecting factors on the synergism activity of $A n L P M 014 \mathrm{~g}$ with cellulase}

In the experiment of the dosage effect of $A n \mathrm{LPMO} 14 \mathrm{~g}$ and cellulase on synergy, three reaction systems were formulated according to Section 2.5. The first reaction system contained different amounts of AnLPMO14g enzyme $(0,0.9,1.8,3.6 \mathrm{~g} / \mathrm{L})$. The second reaction system contained different amounts of cellulase $(0,0.045,0.45,0.9,1.8,3.6 \mathrm{FPU} / \mathrm{mL})$. The third reaction system contained $A n L P M 014 \mathrm{~g}$ and cellulase added in various ratios. In the study of the effect of $\mathrm{pH}$ on the synergy, three reaction systems mentioned above were prepared with different $\mathrm{pH}$ 3-8 using acetate buffer $(\mathrm{pH} 3.5-5.5)$ and sodium phosphate buffer ( $\mathrm{pH}$ 6.0-8.5) at the optimal temperature. In the experiment of metal ion effects on the synergy, $5 \mathrm{mM}$ of different metal ions $\left(\mathrm{Ca}^{2+}, \mathrm{K}^{+}, \mathrm{Cu}^{2+}, \mathrm{Al}^{3+}, \mathrm{Ni}^{2+}, \mathrm{Li}^{2+}\right)$ were added in each of the three systems, and system with no metal ions addition was used as control. Different types of reduced electron donors (ascorbic acid, gallic acid, pyrogallic acid) was used to prepare a reaction system in the study of the effect of reduced electron donor species.

All the reactions were carried out at $50{ }^{\circ} \mathrm{C}, 200 \mathrm{rpm}$ for $48 \mathrm{~h}$ in triplicate. DNS method was used to determine reducing sugar production and DS were calculated. 


\subsection{Sequence alignment and structural modeling}

The sequence alignment of AnLPM014g, AfGH61B from A. fumigatus (PDB code: 6HA5), AfPMO-5 from A. fumigatus (PDB code: 5X6A), Cu-TaGH61 from Thermoascus aurantiacus (PDB code: 2YET),

TVLPM01from Talaromyces verruculosus (PDB code: 7A8V) and HjLPM09A from $H$. jecorina (PDB code: 502W)was generated using Clustal Omega and ESPript (Corpet et al. 1988; Gouet et al. 1999).The homology model of the AnLPMO14g was constructed using SWISS-MODEL (http://swiss model.expasy.org/) with $502 \mathrm{~W}$ as the templates and the predicted protein structures were illustrated using PyMOL (http://www.pymol.org).

\subsection{Statistical analysis}

The results were subjected to Student's t-test analyzes and values of $\mathrm{P}<0.05$ were considered statistically significant. SPSS statistics software (version 22.0, SPSS, Inc., Chicago, US) was used for the statistical analysis. All measurements were performed in triplicate.

\section{Results And Discussion}

\subsection{Production of $A n L P M 014 \mathrm{~g}$}

The total RNA of $A$. niger was successfully extracted and reverse transcribed into cDNA. The pPIC9k recombinant plasmid containing An $14 g 02670$ was successfully constructed by molecular cloning. Highcopy positive clones were obtained by electroporation of Pichia pastoris strains, G418 screening and PCR validation. After induction culture medium cultured positive clones for 4-5 days, the results of SDS-PAGE verification were shown in Fig. S1. Negative control strains containing only empty plasmids showed no significant banding after induction, indicating that $P$. pastoris had no such purpose gene. The corresponding band size of $A n \mathrm{LPM} 014 \mathrm{~g}$ was larger than the theoretical value (36073 Da), probably because of the glycosylation (including $\mathrm{N}$-glycosylation and O-glycosylation) of the gene during expression (Bey et al., 2013). The results showed that $A n L P M 014 \mathrm{~g}$ was successfully expressed, and the purified protein was obtained by purification and dialysis culture supernatant.

\subsection{Substrate specificity of $A n L P M 014 \mathrm{~g}$}

The purified sample was applied to different substrates, and the results of determining the reducing sugar concentration after the reaction was completed were shown in Fig. 1. The results of the action of $A n L P M 014 \mathrm{~g}$ on different substrates indicated that $A n \mathrm{LPMO} 14 \mathrm{~g}$ was able to produce a certain amount of reducing sugars on various substrates, but the yield of reducing sugars when it acting on different substrates was different. The most reducing sugar was produced by hydrolysis of Avicel ${ }^{\circledR}$, followed by straw and xylan; CMC, filter paper and corn cob produced less reducing sugar. It suggested that the structure and composition of the substrate had a great influence on hydrolysis activity of $A n L P M 014 \mathrm{~g}$. 
Avicel® (microcrystalline cellulose) is a purified, partially depolymerized cellulose composed of $\beta$-Dglucopyranose units joined by $\beta-1,4$ glycosidic linkages in a linear arrangement (Rashid et al., 2017); rice straw contains about $30 \%$ Cellulose and $20 \%$ hemicelluloses and xylan is structurally composed predominantly of a $\beta$-D-(1,4)-linked xylopyranosyl residue backbone (Chen et al. 2011; Corradini et al. 2018). This suggested that $A n L P M 014 \mathrm{~g}$ might mainly oxidatively cleave the $\beta$-D-1,4 glycosidic bonds and $\beta-\mathrm{D}-1,4$ xylosidic bonds.

\subsection{Product analysis of cellulose catalyzed by $A$ nLPM014g}

LPMOs have different substrate specificities and vary oxidation region selectivity. LPMOs may only oxidize the $\mathrm{C} 1$ or $\mathrm{C} 4$ carbon in the scissile glycosidic bond, whereas others produce mixtures of $\mathrm{C} 1$ - and C4- oxidation products(Fig. S2a)(Kjaergaard et al. 2014; Walton et al. 2016). The reaction products of Avicel ${ }^{\circledR}$ by $A n L P M 014 \mathrm{~g}$ were analyzed by MALDI-TOF/TOF and the results were shown in Fig. S2b. In the figure, $m / z 689,851,1013,1175,1337$ and 1499 represent sodium addendum of cello-oligosaccharide with degree of polymerization (DP) of 4-9 respectively, which confirmed that $A n L P M O 14 \mathrm{~g}$ could be able to degrade cellulose. $m / z 849,1011,1173$ and 1497 represent the sodium admixture of 1,5-ס-lactone formed by the oxidation of cello-oligosaccharide with DP of 5, 6, 7 and 9, respectively. According to the previous report, 1,5- $\delta$-lactone was instability and usually converted into aldonic acid (Vu et al. 2014; Forsberg et al. 2014). Therefore, $m / z 867,1029$ and 1191 in the figure could be found and they represent the sodium admixture of aldonic acid formed by 1,5- $\delta$-lactone corresponding to cello-pentose, hexose and heptasaccharide oxidation. $m / z 1375$ represents the double sodium aldonic acid admixture of cellooligosaccharide with DP8. There are characteristic peaks of the aldonic acid sodium adjuncts $(M+16$ and $\mathrm{M}+38$ ) that combine one and two sodium in this study. The peaks corresponding to $\mathrm{M}-2$ are more likely to be the unstable lactone existed in the form of aldonic acid rather than 4-ketoaldose (Kim et al. 2017).

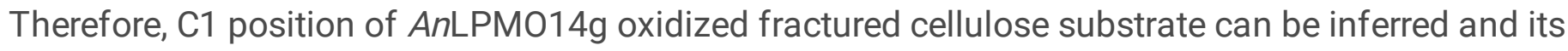
scheme of chemical reaction in the form of $\mathrm{C} 1$ oxidation and C4 oxidation in Fig. S2a.

\subsection{Synergism activity of $A n L P M 014 \mathrm{~g}$ with cellulase}

Avicel ${ }^{\circledR}, \mathrm{CMC}$, straw powder, filter paper and corncob were used as the substrate to conduct synergism activity study and the results were shown in Fig. 2a. It could be seen that the addition of $A n L P M 014 \mathrm{~g}$ significantly increased the yield of reducing sugar compared with the cellulase alone. The yield of reducing sugar obtained by the combination of the two was $92.66 \%$ higher than that of the cellulase alone when Avicel ${ }^{\circledR}$ was used as substrate, and $25.7 \%$ higher than the sum of $A n L P M O 14 \mathrm{~g}$ and cellulase. The DS of $A n L P M 014 \mathrm{~g}$ with cellulase for the degradation of Avicel® was 1.257, indicating that $A n L P M 014 \mathrm{~g}$ and cellulase were not simply superimposed on the degradation of Avicel ${ }^{\circledR}$. This AA9 family of polysaccharide monooxygenases could further promote the degradation of cellulose substrates by traditional cellulases, which was consistent with the properties of LPMO (Zhang et al. 2019). When they acted together on filter paper, the yield of reducing sugar was $43.5 \%$ higher than that of the cellulase 
alone, but the DS of $A n \mathrm{LPM} 014 \mathrm{~g}$ with cellulase on filter paper degradation was up to 1.375. As for CMC, the addition of $A n \mathrm{LPMO} 14 \mathrm{~g}$ increased the yield of reducing sugar by $7.51 \%$ compared to the cellulase alone, which was significantly lower than that of Avicel ${ }^{\circledR}$. Although Avicel ${ }^{\circledR}$, filter paper and $\mathrm{CMC}$ were all cellulosic substrates, $A n L P M 014 \mathrm{~g}$ had different effects on these substrates, which indicated that the structure of the substrate had a great influence on the synergism activity. The synergism activity of $A n \mathrm{LPMO14g}$ with cellulase on filter paper and Avicel ${ }^{\circledR}$ were much higher than that on $\mathrm{CMC}$, which was probably because the presence of carboxymethyl groups in the CMC substrate hindered binding of the cellulase to the substrate.

When $A n L P M 014 \mathrm{~g}$ and cellulase acted together on straw powder, the reducing sugar yield was $141.42 \%$ higher than that of cellulase alone, and the DS was 1.322. While the results when they acting on corncob was $55.37 \%$ higher than that of cellulase alone, and the DS was 1.24 . Therefore, different composition and structure of the lignocellulose substrate significantly influenced the activity of $A n L P M O 14 \mathrm{~g}$ and the synergistic activity between $A n L P M 014 \mathrm{~g}$ and cellulase. Similar results were reported when studying on other LPMO, for example, Basotra et al. found that the improved level of the hydrolysis was different when AA9 LPMO from Malbranchea cinnamomea and commercial cellulase CellicCTec2 acted together on different pretreated biomass samples i.e., acid and alkali treated rice straw (AcRS and AIRS) and bagasse (AcBG and AIBG) (Basotra et al. 2019). Using cocktails of cellulase and AA9 LPMO can greatly improve the degradation rate of lignocellulosic biomass substrate.

\subsection{Major factors affecting the synergistic activity}

All factors were studied with Avicel ${ }^{\circledR}$ as the substrate. Fig. $\mathbf{2 b}$ showed the effect of the dosages of $A n \mathrm{LPMO} 14 \mathrm{~g}$ and cellulase on the yield of reducing sugar. It was worth noting that when the dosage of cellulase was 0 or $0.045 \mathrm{FPU} / \mathrm{g}$, the yield of reducing sugar increased with the dosage of $A n \mathrm{LPMO} 14 \mathrm{~g}$ increased, but when it reached 3.6 FPU/g, the yield of reducing sugar showed a decreasing trend with the

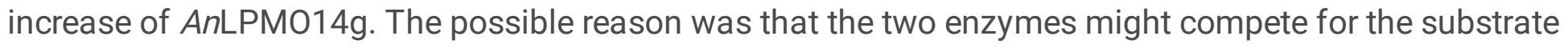
at high enzyme dosage, making the synergy impossible to function properly. This compete can be alleviated by increasing the substrate concentration, but the compete still appeared when the enzyme dosage increased. Similar effects could be seen in Kim's research which studied the synergy between AA9 enzymes from Chaetomium globosa and cellulase, and high AA9 and cellulase dosages were found to cause the competition for substrates (Kim et al. 2015). To further analyze the synergism activity on cellulose, DS of different dosages of $A n L P M O 14 \mathrm{~g}$ and cellulase were calculated in this study and results were shown in Table 1. The synergy degree was greater than 1 when the dosages of $A n L P M 014 \mathrm{~g}$ and cellulase were low, and highest DS of 1.182 was obtained when the dosages of $A n L P M 014 \mathrm{~g}$ and cellulase were $0.9 \mathrm{mg} / \mathrm{g}$ and $0.9 \mathrm{FPU} / \mathrm{g}$, respectively. But when the dosages of $A n \mathrm{LPMO} 14 \mathrm{~g}$ and cellulase increased, DS decreased and most of them were less than 1 . The possible reason is the competition between $A n L P M 014 \mathrm{~g}$ and cellulase on the substrate at high enzyme dosages and low substrate concentration. In addition, DS is also influenced by different substrate from Fig. 2a. Therefore, in order to 
maximize the synergistic effect of LPMO and cellulase in the degradation of cellulose or lignocellulose substrates, it is necessary to control the ratio and the dosages of the cocktail of LPMO and cellulase.

Results of the effect of pH on synergy of $A n L P M 014 \mathrm{~g}$ and cellulase were shown in Fig. 2c. The activity of $A n \mathrm{LPMO} 14 \mathrm{~g}$ or cellulase alone was highly dependent on $\mathrm{pH}$. Reducing sugar production at $\mathrm{pH} 3.0$ was extremely low in all three systems. When $A n L P M 014 \mathrm{~g}$ acted alone, the reducing sugar production was the highest at $\mathrm{pH}$ 4.0; as for cellulase, the highest yield of reducing sugar was obtained at $\mathrm{pH}$ 5.0. While the yield of reducing sugar was highest at $\mathrm{pH} 5.0$ when $A n \mathrm{LPMO} 14 \mathrm{~g}$ and cellulase acted together. And the synergism activity was the highest when $\mathrm{pH}$ was 5.0 and the amount of reducing sugar produced by $A n L P M 014 \mathrm{~g}$ and cellulase was 1.99 times of that by cellulase alone.

The effect of metal ions on reducing sugar production and synergy activity were shown in Fig. $\mathbf{2 d}$. For the system of $A n L P M 014 \mathrm{~g}$ acting alone, the yield of reducing sugar was higher when $\mathrm{Cu}^{2+}$ and $\mathrm{Al}^{3+}$ existed, and the promotion of $\mathrm{Cu}^{2+}$ was the most obvious. The existence of $\mathrm{K}^{+}, \mathrm{Ca}^{2+}, \mathrm{Li}^{2+}$ and $\mathrm{Ni}^{2+}$ inhibited the activity of $A n \mathrm{LPMO} 14 \mathrm{~g}$ on cellulose, and the inhibitory effect of $\mathrm{Ni}^{2+}$ was the most obvious. As for the system of cellulase acting alone, $\mathrm{K}^{+}, \mathrm{Ca}^{2+}$ and $\mathrm{Li}^{2+}$ promoted the cellulase activity while $\mathrm{Cu}^{2+}$ and $\mathrm{Al}^{3+}$ inhibited cellulase activity significantly. For the systems of $A n L P M 014 \mathrm{~g}$ and cellulase acting together, the highest yield of reducing sugar was obtained when no metal ions addition, which was followed by the addition of $\mathrm{Cu}^{2+}$ and $\mathrm{Al}^{3+}$. The addition of other metal ions had no significant effect and $\mathrm{Ca}^{2+}$ would reduce the yield of reducing sugars. As a heavy metal, $\mathrm{Cu}^{2+}$ would cause the inactivation of certain proteins, which might be the reason why it had obvious inhibitory effect on cellulase. However, the addition of $A n \mathrm{LPMO} 14 \mathrm{~g}$ could greatly promote the activity of cellulase to increase the yield of reducing sugar in the existence of $\mathrm{Cu}^{2+}$. The active center of LPMOs was a flat surface with $\mathrm{Cu}^{2+}$ binding sites. On the one hand, $A n L P M 014 \mathrm{~g}$ could bind part of $\mathrm{Cu}^{2+}$ to reduce the inhibition of $\mathrm{Cu}^{2+}$ on cellulase; on the other hand, AnLPMO14g could also degrade cellulose through cleaving the cellulose glycosidic chain by the oxidation mechanism of divalent metal ions ( $\mathrm{Li}$ et al. 2012). It could also be seen that $\mathrm{Ni}^{2+}$ had an inhibitory effect on both $A n L P M O 14 \mathrm{~g}$ and cellulase. Therefore, the expressed crude enzyme must be purified by strict dialysis processing to remove small molecules such as imidazole and metal ions, thereby eliminating the inhibitory influence of $\mathrm{Ni}^{2+}$.

Studies have shown that LPMO of AA9 family needs electrons provided by external electron donor to reduce $\mathrm{Cu}(\mathbb{\nabla})$ in the active center to $\mathrm{Cu}(\mathbb{\nabla})$ when it oxidatively cleaves the glycosidic bond (Hemsworth et al. 2015). According to the way they provide electrons and their molecular structure characteristics, exogenous electron donors can be classified into three types: a number of reducing small molecules, some oxidoreductases with flavin as a prosthetic group and some light-sensitive organic or inorganic substances (Walton et al. 2016). As the reducing small molecules can directly provide electrons with high efficiency and simple application, they were used in this work and their effect on the activity of

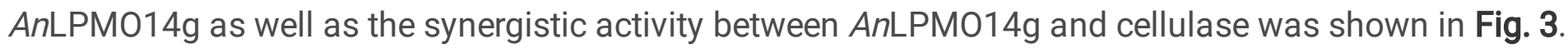
All of them could promote the activity of $A n L P M 014 \mathrm{~g}$ and the synergism activity of $A n L P M 014 \mathrm{~g}$ with cellulase. Among them, the promotion effect of ascorbic acid was the highest. Simmons et al. reported 
similar results that the cleavages of MLG, glucomannan and xyloglucan by LSAA9A were sensitive to reducing agent potential, with ascorbate as reductant yielding much higher amount of product (Simmons et al. 2017). The effect of gallic acid and pyrogallic acid was not significant. The reason might be that the latter two had weak reduction ability, and they were not stable enough to provide the electrons and reducing power required for normal functioning of $A n L P M 014 \mathrm{~g}$.

\subsection{Sequence alignment and structural modeling}

To investigate the potential function of $A n L P M 014 \mathrm{~g}$ as the common activity of AA9 family, sequence alignment and homology modeling were performed. From Fig.4a, the sequence alignment of $A n \mathrm{LPMO} 14 \mathrm{~g}$ exhibited high similarity to those of the referred AA9s with known structures, especially to HJLPMO9A (sequence identity of $58.19 \%$ ). In addition, amino acid residues that were reported to be highly conserved in other AA9s (His1, His86, and Tyr175) were also contained in AnLPM014g (Fig. 4b). These conserved residues are divalent metal-binding residues that are known to be important for enzyme activity (Quinlan et al. 2011; Hansson et al. 2017; Leggio et al. 2018).

Using HJLPMO9A as the template, the predicted structure of $A n L P M 014 \mathrm{~g}$ by homology modeling was revealed to possess an immunoglobulin-like $\beta$-sandwich fold which consisted of two $\beta$-sheets formed by eight $\beta$-strands and the conserved metal-binding sites ( $\mathrm{HIC1}$, His86, and Tyr175) were observed on the surface. In addition, the two nitrogen atoms on the N-terminal histidine ( $2.0 \AA$ and $2.3 \AA$ from copper ion, respectively) and the nitrogen atom on histidine at 86 site (2.1 $\AA$ from copper ion) formed the so-called "histidine brace" (Fig. 4c) (Hansson et al., 2017), which was first revealed and named by Quinlan and similar to the particulate methane monooxygenase (Lieberman et al. 2005; Cao et al. 2018). Oxygen atoms of a tyrosine $(2.9 \AA)$ and a above water molecule $(2.4 \AA)$ occupied the apical positions and completed the immediate coordination sphere (Fig. 4d) (Hansson et al. 2017). additionally, the metal binding motif and the putative cellulose-binding surface of $A n L P M 014 \mathrm{~g}$ were superimposed with those of other AA9 homologs (Fig. 4b). The three metal-binding sites in AnLPM014g were structurally conserved among AA9 homologs.

Notably, N-terminal histidine that binds to copper is modified by methylation, and histidine methylation has been reported in the PDB, with the code of HIC. Although the phenomenon that N-terminal histidine methylation had been ignored in earlier crystallographic researches (Harris et al. 2010; Karkehabadi et al. 2008), current studies have shown that this modification has little effect on the catalytic properties of enzymes but may help to protect LPMOs from the autocatalytic oxidation damage (Petrovi et al. 2018). furthermore, three regions with high B-factors in the structure of $A n L P M 014 \mathrm{~g}$ were observed, which was named as chain $A(P 23-P 29)$, chain $B(L 120-G 127)$ and chain $C(Y 212-1221)$. From Fig.4a, the chain $A$ in AnLPM014g were highly conserved in the structures among AA9 homologs, which may help the enzyme to maintain catalytic activity at high temperature. Interestingly, the current studies found that in all cases the active site residues predominantly occurred in the low B-factor region, while the residues within the binding pocket tend to be present in the high B-factor region, which provides a novel thinking for 
improving the catalytic efficiency of LPMOs by site-directed mutation (Guo et al. 2012; Alvarezi et al. 2014; Gaspar et al. 2012; Yang et al. 2005).

\section{Conclusion}

In this study, AnLPM014g, an AA9 polysaccharide monooxygenase from A. niger was successfully cloned and expressed. It could act on Avicel ${ }^{\circledR}, \mathrm{CMC}$, filter paper, lignocellulose (straw, corn cob) and xylan substrate, and oxidatively cleaved the polysaccharide chain of cellulose at C1 position. Synergistic effect was obvious between $A n \mathrm{LPMO} 14 \mathrm{~g}$ and cellulase when acting on Avice ${ }^{\circledR}$, filter paper and lignocellulose at low enzyme dosages. Enzyme dosages, $\mathrm{pH}$, metal ion, and the type and concentration of reducing electron donor had different effects on synergism activity. Finally, the optimal model was demonstrated that the residues of active site $(\mathrm{H} 1, \mathrm{H} 86$ and $\mathrm{Y} 175)$ as well as the residues of $\mathrm{Y} 24, \mathrm{P} 83$ and $\mathrm{Y} 212$ played an important role in substrate binding, which was an optimal basis for further directed evolution. This study could expand the source range of AA9 polysaccharide monooxygenase, which was of great significance for the study of polysaccharide monooxygenase and the degradation of lignocellulose.

\section{Declarations}

\section{Competing interests}

The authors declare that they have no competing interests.

\section{Declaration of interests}

The authors declare that they have no known competing financial interests or personal relationships that could have appeared to influence the work reported in this paper.

\section{Acknowledgements}

This work was support by the National Natural Science Foundation of China (31770625), the Key Research and Development Program of Ningxia Hui Autonomous Region (No. 2020BFH02006), and the Key Laboratory of Wuliangye-flavor Liquor Solid-state Fermentation, China National Light Industry (No. 2021zd010).

\section{References}

1. Jonsson LJ, Alriksson B, Nilvebrant NO (2013) Bioconversion of lignocellulose: inhibitors and detoxification. Biotechnol Biofuels 6:16. https://doi.org/10.1186/1754-6834-6-16.

2. Lynd LR, ZyI WHV, McBride JE, Laser M (2005) Consolidated bioprocessing of cellulosic biomass: an update. Curr Opin Biotechnol 16:577-583. https://doi.org/10.1016/j.copbio.2005.08.009.

3. Cheng JJ, Timilsina GR (2011) Status and barriers of advanced biofuel technologies: A review. Renew Energ 36:3541-3549. https://doi.org/10.1016/j.renene.2011.04.031. 
4. Payne CM, Knott, B.C., Mayes HB, Hansson H, Himmel ME, Sandgren M, Stahlberg J., Beckham GT (2015) Fungal Cellulases. Chem Rev 115:1308-1448. https://doi.org/10.1021/cr500351c.

5. Reese ET, Siu RGH, Levinson HS (1950) The biological degradation of soluble cellulose derivatives and its relationship to the mechanism of cellulose hydrolysis. J Bacteriol 59: 485-497. https://doi.org/10.1128/jb.59.4.485-497.1950.

6. Harris PV, Welner D, McFarland KC, Re E, Poulsen JCN, Brown K, Salbo R, Ding H, Vlasenko E, Merino S, Xu F, Cherry J, Larsen S, Leggio LL (2010) Stimulation of Lignocellulosic Biomass Hydrolysis by Proteins of Glycoside Hydrolase Family 61: Structure and Function of a Large, Enigmatic Family. Biochemistry 49:3305-3316. https://doi.org/10.1021/bi100009p.

7. Kim ES, Lee HJ, Bang WG, Choi IG, Kim KH (2009) Functional Characterization of a Bacterial Expansin From Bacillus subtilis for Enhanced Enzymatic Hydrolysis of Cellulose. Biotechnol. Bioeng. 102:1342-1353. https://doi.org/10.1002/bit.22193.

8. Levasseur A, Drula E, Lombard V, Coutinho PM, Henrissat B (2013) Expansion of the enzymatic repertoire of the CAZy database to integrate auxiliary redox enzymes. Biotechnol Biofuels 6:41. https://doi.org/10.1186/1754-6834-6-41.

9. Forsberg Z, Vaaje-Kolstad G, Westereng B, Bunaes AC, Stenstrom Y, MacKenzie A, Sorlie M, Horn SJ, Eijsink VGH (2011) Cleavage of cellulose by a CBM33 protein. Protein Sci 20:1479-1483. https://doi.org/10.1002/pro.689.

10. Beeson WT, Phillips CM, Cate JHD, Marletta MA (2012) Oxidative Cleavage of Cellulose by Fungal Copper-Dependent Polysaccharide Monooxygenases. J Am Chem Soc 134:890-892. https://doi.org/10.1021/ja210657t.

11. Vaaje-Kolstad G, Forsberg Z, Loose JSM, Bissaro B, Eijsink VGH (2017) Structural diversity of lytic polysaccharide monooxygenases. Curr Opin Struct Biol 44:67-76. https://doi.org/10.1016/j.sbi.2016.12.012.

12. Karkehabadi S, Hansson H, Kim S, Piens K, Mitchinson C, Sandgren M (2008) The First Structure of a Glycoside Hydrolase Family 61 Member, Cel61B from Hypocrea jecorina, at 1.6 angstrom Resolution. J Mol Biol 383:144-154. https://doi.org/10.1016/j.jmb.2008.08.016.

13. Borisova AS, Isaksen T, Dimarogona M, Kognole AA, Mathiesen G, Varnai A, Rohr AK, Payne CM, Sorlie M, Sandgren M, Eijsink VGH (2015) Structural and Functional Characterization of a Lytic Polysaccharide Monooxygenase with Broad Substrate Specificity. J Biol Chem 290:22955-22969. https://doi.org/10.1074/jbc.M115.660183.

14. Agger JW, Isaksen T, Varnai A, Vidal-Melgosa S, Willats WGT, Ludwig R, Horn SJ, Eijsink VGH, Westereng B (2014) Discovery of LPMO activity on hemicelluloses shows the importance of oxidative processes in plant cell wall degradation. P Natl Acad Sci USA 111:6287-6292. https://doi.org/10.1073/pnas.1323629111.

15. Hu J, Arantes V, Pribowo A, Gourlay K, Saddler JN (2014) Substrate factors that influence the synergistic interaction of $A A 9$ and cellulases during the enzymatic hydrolysis of biomass. Energy Environ Sci 7:2308-2315. https://doi.org/10.1039/C4EE00891J. 
16. Jung S, Song Y, Kim HM, Bae HJ (2015) Enhanced lignocellulosic biomass hydrolysis by oxidative Iytic polysaccharide monooxygenases (LPMOs) GH61 from Gloeophyllum trabeum. Enzyme Microb Technol 77:38-45. https://doi.org/10.1016/j.enzmictec.2015.05.006.

17. Tanghe M, Danneels B, Camattari A, Glieder A, Vandenberghe I, Devreese B, Stals I, Desmet T (2015) Recombinant Expression of Trichoderma reesei Cel61A in Pichia pastoris: Optimizing Yield and Nterminal Processing. Mol Biotechnol 57:1010-1017. https://doi.org/10.1007/s12033-015-9887-9.

18. Kim IJ, Nam KH, Yun EJ, Kim S, Youn HJ, Lee HJ, Choi IG, Kim KH (2015) Optimization of synergism of a recombinant auxiliary activity 9 from Chaetomium globosum with cellulase in cellulose hydrolysis. Appl Microbiol Biotechnol 99:8537-8547. https://doi.org/10.1007/s00253-015-6592-3.

19. Li X, Beeson WT, Phillips CM, Marletta MA, Cate JHD (2012) Structural Basis for Substrate Targeting and Catalysis by Fungal Polysaccharide Monooxygenases. Structure 20:1051-1061. https://doi.org/10.1016/j.str.2012.04.002.

20. Kjaergaard CH, Qayyum MF, Wong SD, Xu F, Hemsworth GR, Walton DJ, Young NA, Davies GJ, Walton $\mathrm{PH}$, Johansen KS, Hodgson KO, Hedman B, Solomon El (2014) Spectroscopic and computational insight into the activation of $\mathrm{O}_{2}$ by the mononuclear $\mathrm{Cu}$ center in polysaccharide monooxygenases. $\mathrm{P}$ Natl Acad Sci USA 111:8797-8802. https://doi.org/10.1073/pnas.1408115111.

21. Tan TC, Kracher D, Gandini R, Sygmund C, Kittl R, Haltrich D, Hallberg BM, Ludwig R, Divne C (2015) Structural basis for cellobiose dehydrogenase action during oxidative cellulose degradation. Nat Commun 6:7542. https://doi.org/10.1038/ncomms8542.

22. Du L, Ma L, Ma Q, Guo G, Han X, Xiao D (2018) Hydrolytic boosting of lignocellulosic biomass by a fungal lytic polysaccharide monooxygenase, AnLPM015g from Aspergillus niger. Ind Crop Prod 126:309-315. https://doi.org/10.1016/j.indcrop.2018.10.029.

23. Miller GL (1959) Use of Dinitrosalicylic Acid Reagent for Determination of Reducing Sugar. Anal Chem 31:426-428. https://doi.org/10.1021/ac60147a030.

24. Corpet $F$ (1988) Multiple sequence alignment with hierarchical clustering. Nucleic Acids Res 16:10881-90. https://doi.org/10.1093/nar/16.22.10881.

25. Gouet P, Courcelle E, Stuart DI, Metoz F (1999) ESPript: analysis of multiple sequence alignments in PostScript. Bioinformatics 15:305-8. https://doi.org/10.1093/bioinformatics/15.4.305.

26. Bey M, Zhou S, Poidevin L, Henrissat B, Coutinho PM, Berrin JG, Sigoillot JC (2013) CelloOligosaccharide Oxidation Reveals Differences between Two Lytic Polysaccharide Monooxygenases (Family GH61) from Podospora anserina. Appl Environ Microbiol 79:488-496. https://doi.org/10.1128/AEM.02942-12.

27. Rashid M, Gafur MA, Sharafat MK, Minami H, Miah MAJ, Ahmad H (2017) Biocompatible microcrystalline cellulose particles from cotton wool and magnetization via a simple in situ coprecipitation method. Carbohydr Polym 170:72-79. https://doi.org/10.1016/j.carbpol.2017.04.059.

28. Chen WH, Pen BL, Yu CT, Hwang WS (2011) Pretreatment efficiency and structural characterization of rice straw by an integrated process of dilute-acid and steam explosion for bioethanol production. Bioresour Technol 102:2916-2924. https://doi.org/10.1016/j.biortech.2010.11.052. 
29. Corradini FAS, Baldez TO, Milessi TSS, Tardioli PW, Ferreira AG, Giordano Rd C, Giordano Rd LC (2018) Eucalyptus xylan: An in-house-produced substrate for xylanase evaluation to substitute birchwood xylan. Carbohydr Polym 197:167-173. https://doi.org/10.1016/j.carbpol.2018.05.088.

30. Walton PH, Davies GJ (2016) On the catalytic mechanisms of lytic polysaccharide monooxygenases. Curr Opin Chem Biol 31:195-207. http://dx.doi.org/10.1016/j.cbpa.2016.04.001.

31. Simmons TJ, Frandsen KEH, Ciano L, Tryfona T, Lenfant N, Poulsen JC, Wilson LFL, Tandrup T, Tovborg M, Schnorr K, Johansen KS, Henrissat B, Walton PH, Leggio LL, Dupree P (2017) Structural and electronic determinants of lytic polysaccharide monooxygenase reactivity on polysaccharide substrates. Nat Commun 8:1064. https://doi.org/10.1038/s41467-017-01247-3.

32. Quinlan RJ, Sweeney MD, Leggio LL, Otten H, Poulsen JCN, Johansen KS, Krogh KBRM, Jrgensen Cl, Tovborg M, Anthonsen A (2011) Insights into the oxidative degradation of cellulose by a copper metalloenzyme that exploits biomass components. P Natl Acad Sci 108:15079-15084. https://doi.org/10.1073/pnas.1105776108.

33. Lieberman R, Rosenzweig A (2005) Crystal structure of a membrane-bound metalloenzyme that catalyses the biological oxidation of methane. Nature 434(7030):177-182. https://doi.org/10.1038/nature03311.

34. Cao L, Caldararu O, Rosenzweig AC, Ryde U (2018) Quantum Refinement Does Not Support Dinuclear Copper Sites in Crystal Structures of Particulate Methane Monooxygenase. Angewandte Chemie 57(1):168-172. https://doi.org/10.1002/anie.201708977.

35. Petrovi DM, Bastien B, Piotr C, Morten S, Morten S, Jensen MS, Aachmann FL, Courtade G, Varnai A, Eijsink' VGH (2018) Methylation of the n-terminal histidine protects a lytic polysaccharide monooxygenase from auto-oxidative inactivation. Protein Sci 27:1636-1650. https://doi.org/10.1002/pro.3451.

36. Schlessinger A, Yachdav G, Rost B (2006) PROFbval: Predict flexible and rigid residues in proteins. Bioinformatics. 22, 891-893. https://doi.org/10.1093/bioinformatics/btl032.

37. Guo X, He D, Ling H, Liu L, Liu L, Yang H (2012) Strain energy in enzyme-substrate binding: an energetic insight into the flexibility versus rigidity of enzyme active site. Comput Theor Chem 995:1723. https://doi.org/10.1016/j.comptc.2012.06.017.

38. Alvarez GD, Barril X (2014) Relationship between protein flexibility and binding: lessons for structurebased drug design. J Chem Theory Comput 10(6):2608. https://doi.org/10.1021/ct500182z.

39. Gaspar ME, Peter C (2012) Rigidity and flexibility of biological networks. Brief Funct Genomics 11(6):443-456. https://doi.org/10.1093/bfgp/els023.

40. Yang LW, Bahar I (2005) Coupling between catalytic site and collective dynamics: a requirement for mechanochemical activity of enzymes. Structure 13(6):893-904. https://doi.org/10.1016/j.str.2005.03.015.

41. Hansson H, Karkehabadi S, Mikkelsen N, Douglas NR, Kim S, Lam A, Kaper T, Kelemen B, Meier KK, Jones SM (2017) High-resolution structure of a lytic polysaccharide monooxygenase from Hypocrea 
jecorina reveals a predicted linker as an integral part of the catalytic domain. J Biol Chem 292:1909919109. https://doi.org/10.1074/jbc.M117.799767.

42. Leggio LL, Weihe CD, Poulsena JCN, Sweeneyb M, Rasmussenb F, Lin J, Maria LD, Wogulis M (2018) Structure of a lytic polysaccharide monooxygenase from Aspergillus fumigatus and an engineered thermostable variant. Carbohyd Res 469:55-59. https://doi.org/10.1016/j.carres.2018.08.009.

\section{Tables}

Table 1 Synergism degrees of $A n L P M 014 \mathrm{~g}$ with cellulase when acting on Avicel ${ }^{\circledR}$.

\begin{tabular}{|llllll|}
\hline AnLPMO14g $(\mathrm{mg} / \mathrm{g})$ & \multicolumn{5}{l|}{ Cellulase $(\mathrm{FPU} / \mathrm{g})$} \\
\cline { 2 - 6 } & 0.045 & 0.45 & 0.9 & 1.8 & 3.6 \\
\hline 0.9 & 1.024 & 1.086 & 1.182 & 0.929 & 0.758 \\
\hline 1.8 & 1.083 & 0.964 & 0.874 & 0.755 & 0.654 \\
\hline 3.6 & 1.160 & 0.750 & 1.007 & 0.693 & 0.502 \\
\hline
\end{tabular}

\section{Figures}




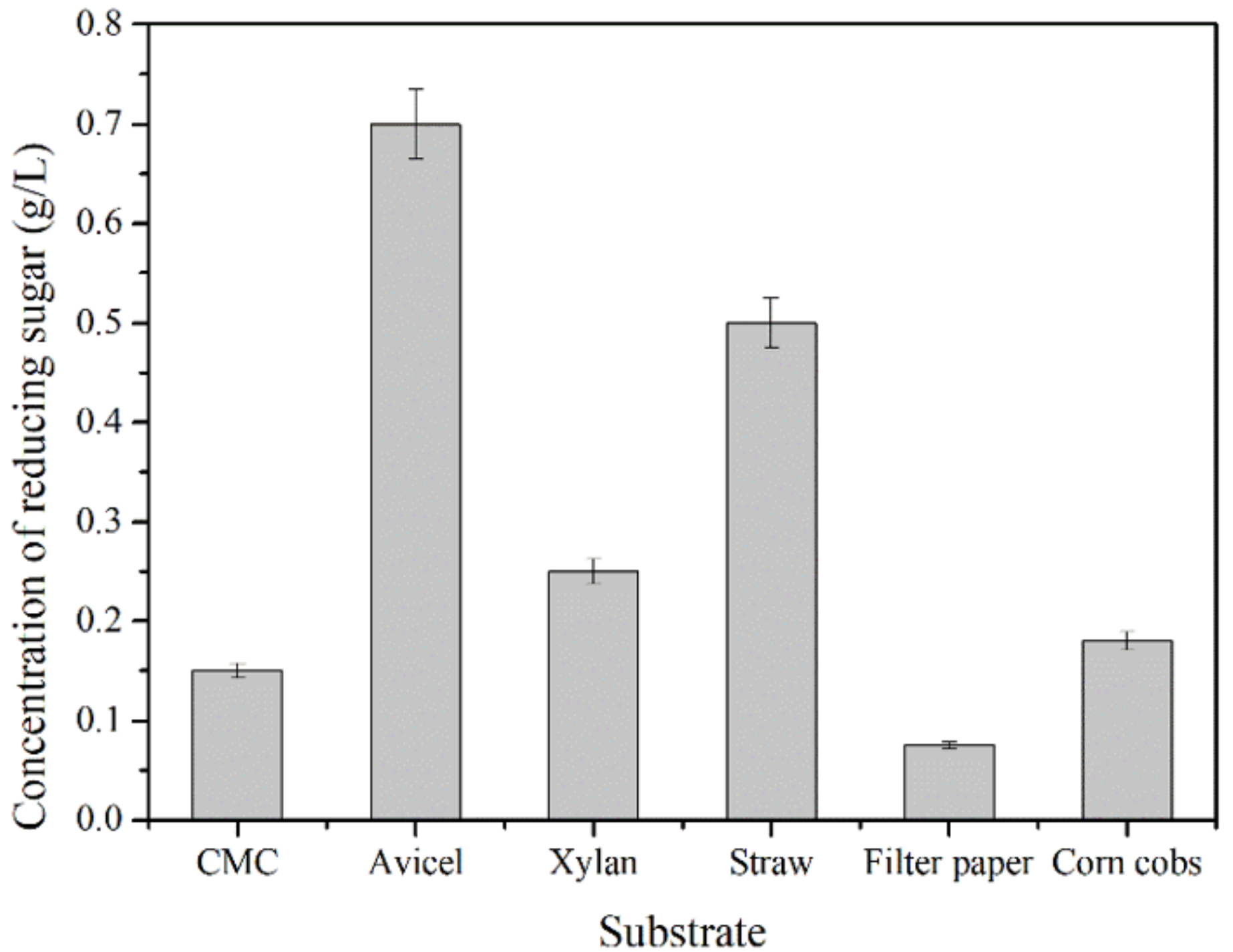

Figure 1

Reducing sugar yield of different substrates hydrolyzed by $A n L P M O 14 \mathrm{~g}$ 
a

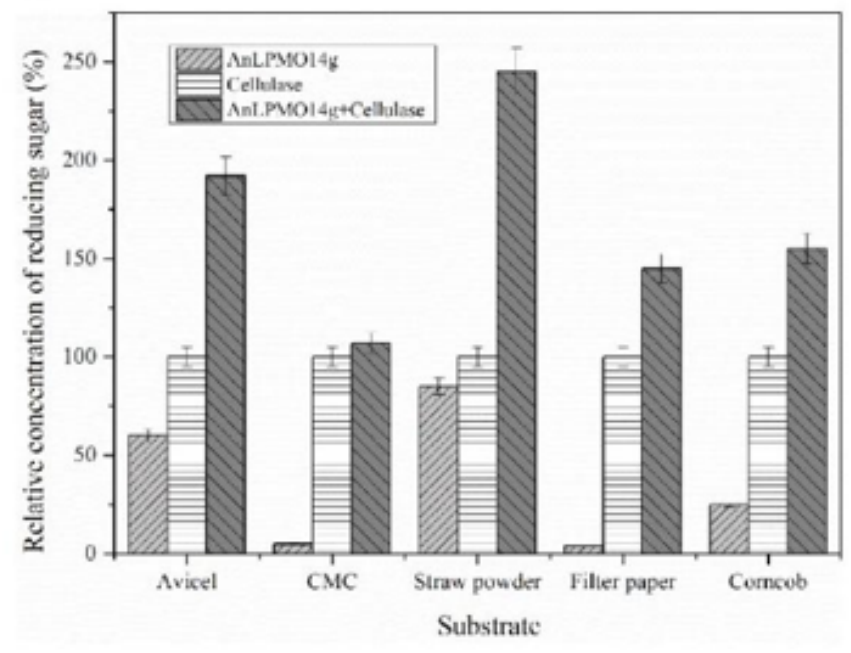

C

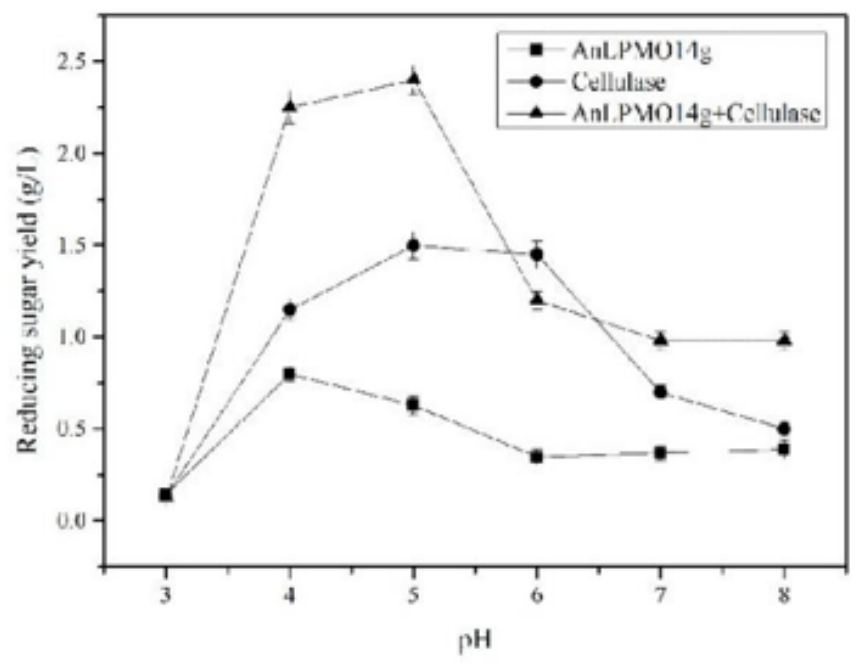

b

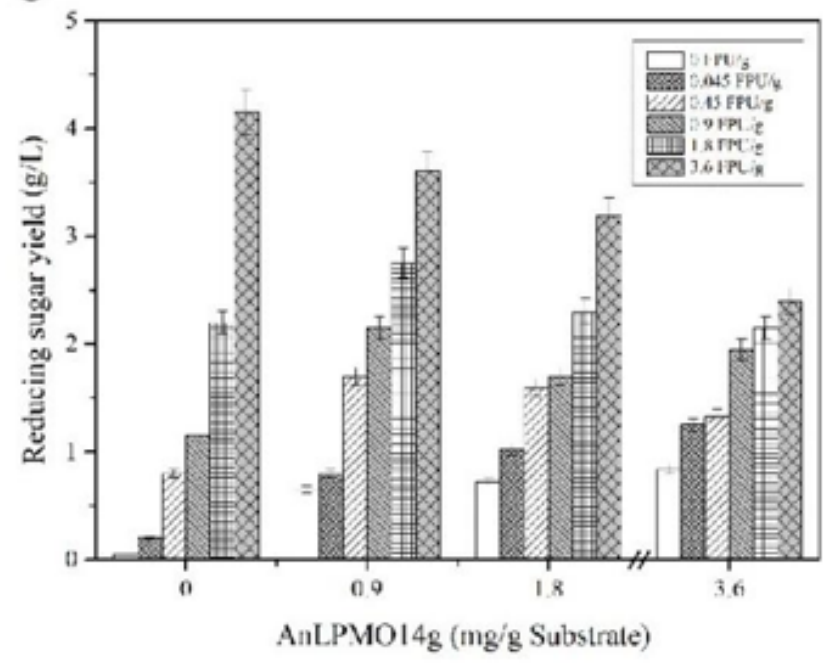

d

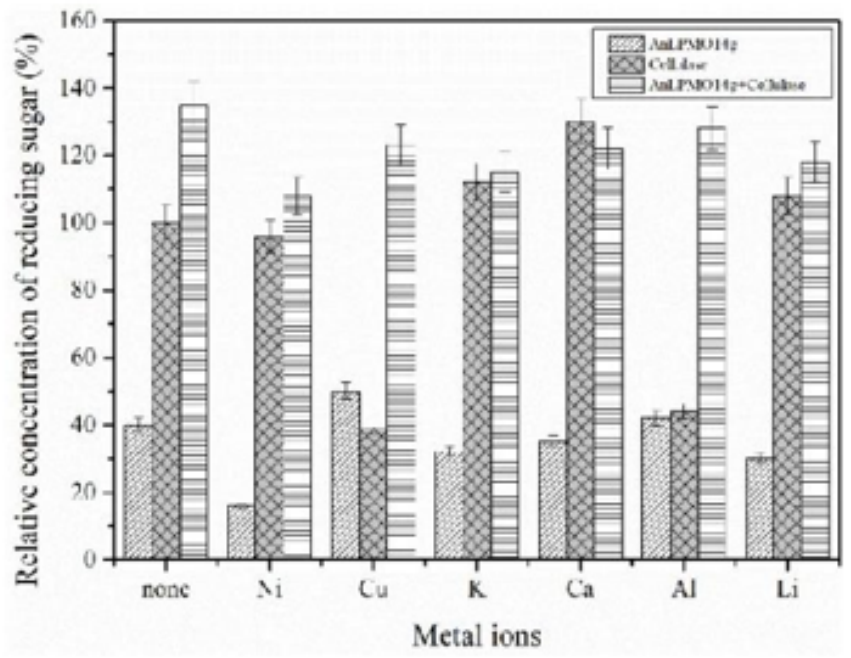

Figure 2

(a) Synergism activity of $A n \mathrm{LPMO} 14 \mathrm{~g}$ with cellulase on Avicel ${ }^{\circledR}, \mathrm{CMC}$, straw powder, filter paper and corncob.(b) Influence of dosage of $A n L P M O 14 \mathrm{~g}$ and cellulase on synergism activity.(c) Influence of pH on the reducing sugar yield of cellulose by $A n \mathrm{LPMO} 14 \mathrm{~g}$ and cellulase individually and together.(d) Influence of metal ions on the reducing sugar yield and synergism activity. 


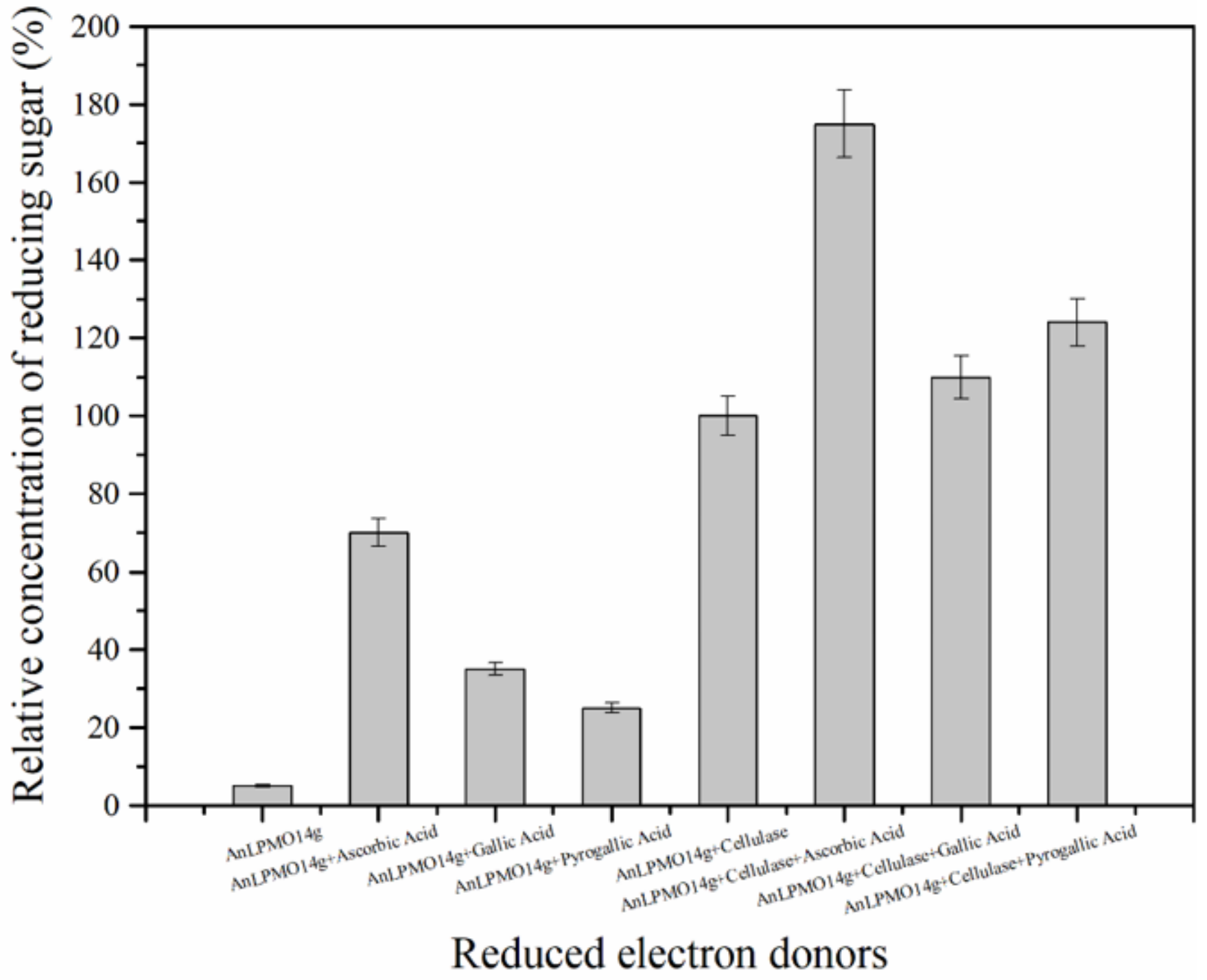

Figure 3

Influence of different electron donor on the activity of $A n \mathrm{LPMO} 14 \mathrm{~g}$ and the synergism activity of AnLPM014g with cellulase. 


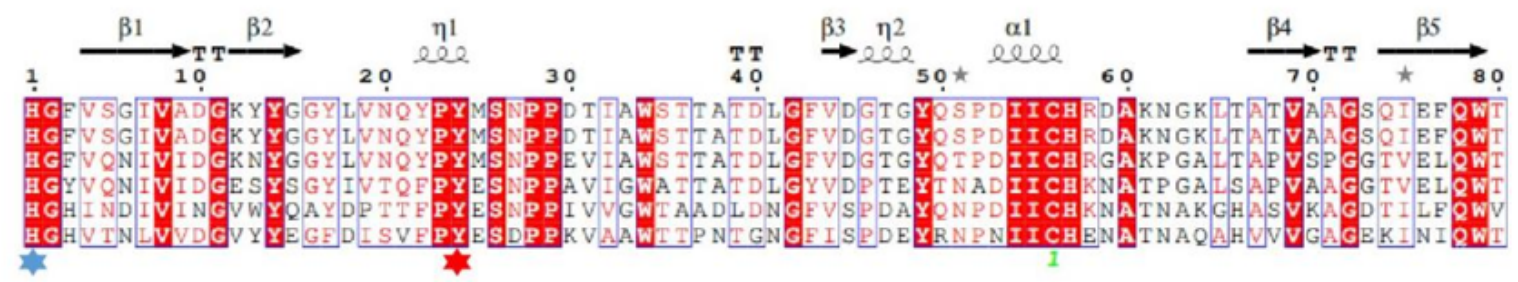

AfGH61B AJPMO-5 Cu-TaGH61 TvLPMO1 HJLPMO9A AnLPMO14g

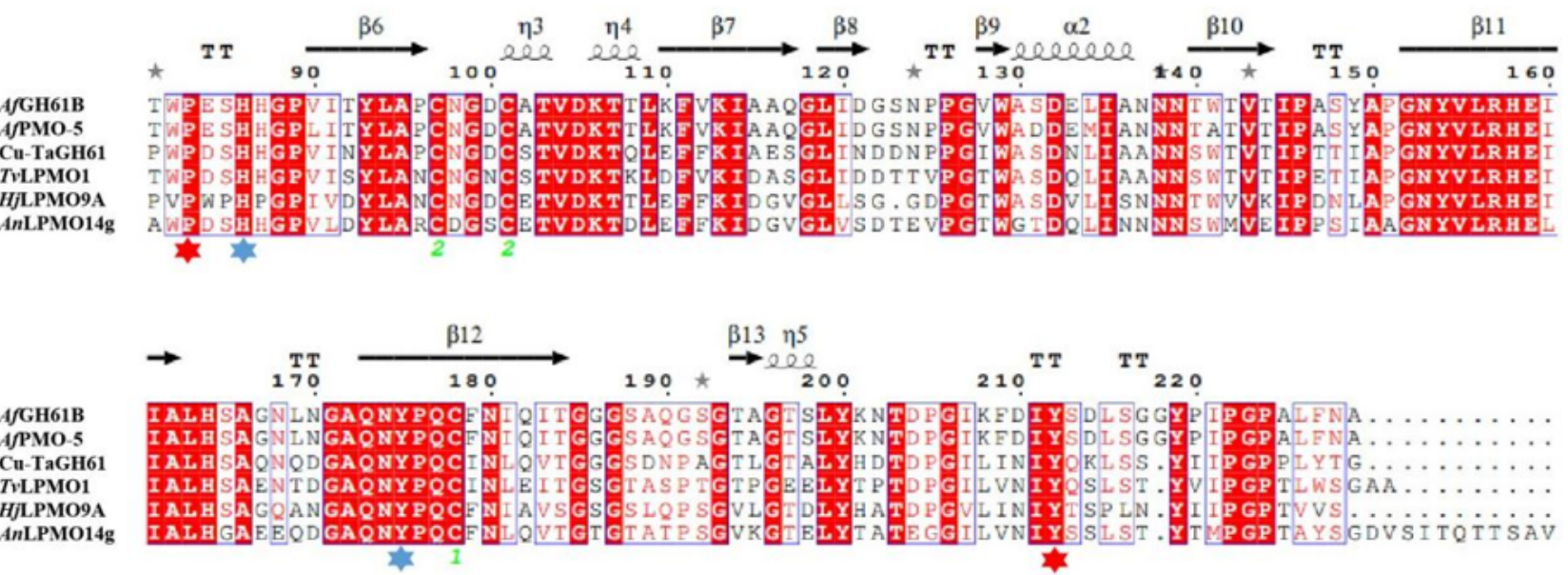

b

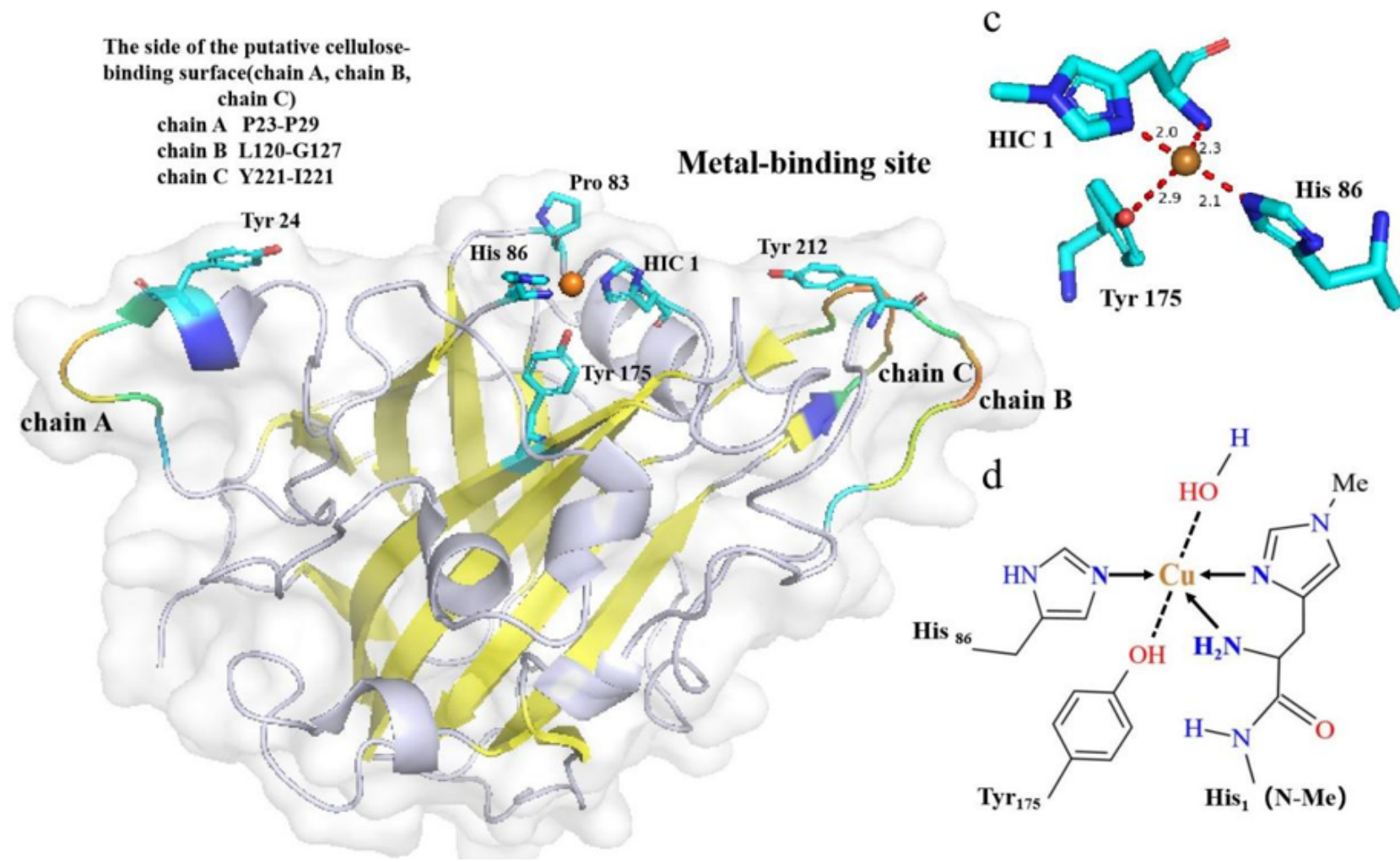

Figure 4

Multiple alignments of $A n L P M 014 \mathrm{~g}$ with other closely related LPMOs. Secondary structure elements of $A n L P M 014 \mathrm{~g}$ are indicated above the sequences. Conserved residues are shown as red characters in boxes with blue lines; identical residues are shown as white characters on a red background. Disulfide bridges are identified by green numbers. The residues that form the metal binding site and the putative substrate binding sites are marked with blue and red asterisks, respectively. The signal peptide sequence 
(Met1-Ala21) of $A n \mathrm{LPMO14 \textrm {g }}$ is not shown in the figure. This figure is prepared using Clustal Omega tool and ESPript (a) and cartoon representation of the structural model of $A n L P M 014 \mathrm{~g}$. The functionally important residues are shown as sticks. The highly conserved metal-binding motifs (His1, His 86, and Tyr175) and the putative substrate-binding sites (Tyr24, Pro83, and Tyr212) are shown as sticks in blue. The side of the putative cellulose-binding surface (chain A, chain B, and chain C) are shown as cartoon in B-factors (b) and the highly conserved metal-binding motifs ( $\mathrm{HIC1}$, His 86, and Tyr175) are shown at a distance from copper ions (c) and schematic diagram of the copper site in AnLPMO14g, depicting "histidine brace" (d).

\section{Supplementary Files}

This is a list of supplementary files associated with this preprint. Click to download.

- supplementarymaterial.docx 